\title{
A Pequena Cidade e o Agronegócio: o caso de Canitar - SP
}

\author{
The Small Town and Agribusiness: the case of Canitar - SP \\ El Pequeño Pueblo y la Agroindustria: el caso de Canitar - SP \\ Franciele Ferreira Dias ${ }^{1}$ \\ https://orcid.org/0000-0001-8860-1844
}

\begin{abstract}
RESUMO: O objetivo do trabalho é discutir os desdobramentos econômicos e sociais decorrentes da participação da pequena cidade de Canitar, na cadeia produtiva que envolve o agronegócio da canade-açúcar. Em Canitar aproximadamente $85 \%$ da área municipal é ocupada por esse cultivo, há uma expressiva concentração de terras e ausência de outras atividades econômicas agropecuárias relevantes. Em decorrência, a monocultura da cana-de-açúcar gera poucos empregos e renda insuficiente à população, o que se manifesta nas atividades econômicas urbanas, bastante restritas, configurando-se por uma estagnação econômica, que se revela também na manutenção dos serviços e infraestruturas básicas. A participação de Canitar na cadeia produtiva da cana-de-açúcar pauta-se no cultivo e na disponibilização de mão-de-obra para as funções com piores remunerações. Para a realização do trabalho, além da revisão bibliográfica, foram realizados dois trabalhos de campo na cidade, ocasião em que se coletaram informações e dados, e realizaram-se entrevistas e registro fotográfico.
\end{abstract}

PALAVRAS-CHAVES: Pequenas cidades. Cana-de-açúcar. Agronegócio.

ABSTRACT: The objective of this work is to discuss the economic and social developments resulting from the participation of the small town of Canitar in the productive chain that involves the sugarcane agribusiness. In Canitar, approximately $85 \%$ of the municipal area is occupied by this cultivation, there are an expressive land concentration and the absence of other relevant agricultural economic activities. Canitar's participation in the sugar cane production chain is based on its cultivation and the availability of workforce for most low-paid jobs. In order to conduct the work, in addition to the bibliographic review, two field studies were carried out in the town to collect information and data, besides interviews and photographic records. As a result, sugarcane monoculture generates few jobs and insufficient income for the population, which is manifested in quite restricted urban economic activities, resulting in economic stagnation that reveals itself also in the preserving of basic services and infrastructures.

KEYWORDS: Small tows. Sugar cane. Agribusiness.

\footnotetext{
${ }^{1}$ Doutora em Geografia pela Universidade Estadual de Londrina e Professora Substituta no Curso de Geografia da Unesp (Campus de Ourinhos).E-mail: franciele.ferreira-dias@unesp.br.
} 
RESUMEN: El objetivo del trabajo es discutir los despliegues económicos y sociales resultantes de la participación del pequeño poblado de Canitar, en la cadena productiva que involucra la agroindustria de la caña de azúcar. En Canitar aproximadamente el 85\% del área municipal está ocupada por esta cultura, hay una expresiva concentración de tierras y la ausencia de otras actividades económicas agropecuarias relevantes. La participación de Canitar en la cadena productiva de la caña de azúcar se basa en el cultivo y la disponibilidad de mano de obra para los trabajos más mal pagados. Para llevar a cabo el trabajo, además de la revisión bibliográfica, se realizaron dos trabajos de campo en la ciudad, en los que se recogió informaciones y datos, se realizó entrevistas y registro fotográfico. Como resultado, el monocultivo de la caña de azúcar genera pocos empleos e ingresos insuficientes para la población, lo que se manifiesta en actividades económicas urbanas, las cuales son bastante restringidas, caracterizándose por un estancamiento económico, que también se manifiesta en el mantenimiento de servicios e infraestructura básico.

PALABRAS CLAVES: Pequeñas ciudades. Caña de azúcar. Agroindustria.

\section{INTRODUÇÃO}

No Brasil, os estudos sobre as pequenas cidades ainda são pouco numerosos, dada a aparente pouca complexidade e imutabilidade econômica e social que esses núcleos urbanos expressariam. Porém há alguns trabalhos que seguem na contramão, podendo citar Fresca (1993), Veiga (2007) e Endlich (2006), os quais revelam a singularidade que esse escalão urbano pode desempenhar. Desse modo, o objeto de estudo do trabalho é a pequena cidade de Canitar, cuja população é 5.292 habitantes (IBGE, 2020a), inserida na região Centro-Oeste Paulista (FUNDAÇÃO SEADE; EMPRESA PAULISTA DE PLANEJAMENTO METROPOLITANO, 2011). Na figura 1 observa-se a localização geográfica de Canitar, a 373 quilômetros da capital São Paulo.

O trabalho é resultado da tese de doutorado da autora (FERREIRA DIAS, 2019) e tem como objetivo discutir os desdobramentos econômicos e sociais resultantes da participação do município de Canitar, na cadeia produtiva do agronegócio da cana-de-açúcar. Em linhas gerais, essa cadeia produtiva envolve o cultivo, processamento industrial e transformação em açúcar e etanol, distribuição da produção e a comercialização no mercado interno ou exportação. Nesse sentido, o trabalho discute a participação de Canitar nesse processo e os elementos econômicos e sociais, resultantes, sobretudo, no espaço urbano.

A problemática que motiva o trabalho relaciona-se à extensão do cultivo de cana-deaçúcar em Canitar, pois o município, cujo tamanho é de 57,38 quilômetros quadrados ou 5.738 hectares, apresenta 4.429 hectares ocupados pelo cultivo (IBGE, 2017a), o que representa $77,38 \%$ da área total do município, denotando uma expressiva concentração de terras, na medida em que há 32 estabelecimentos rurais e um deles soma 4.145 hectares. Esses fatores refletem-se no espaço urbano de Canitar, pois há falta de empregos, setor 
industrial quase inexistente, comércio e serviços pouco complexos, devido à baixa renda da população local.

Figura 1- Localização de Canitar

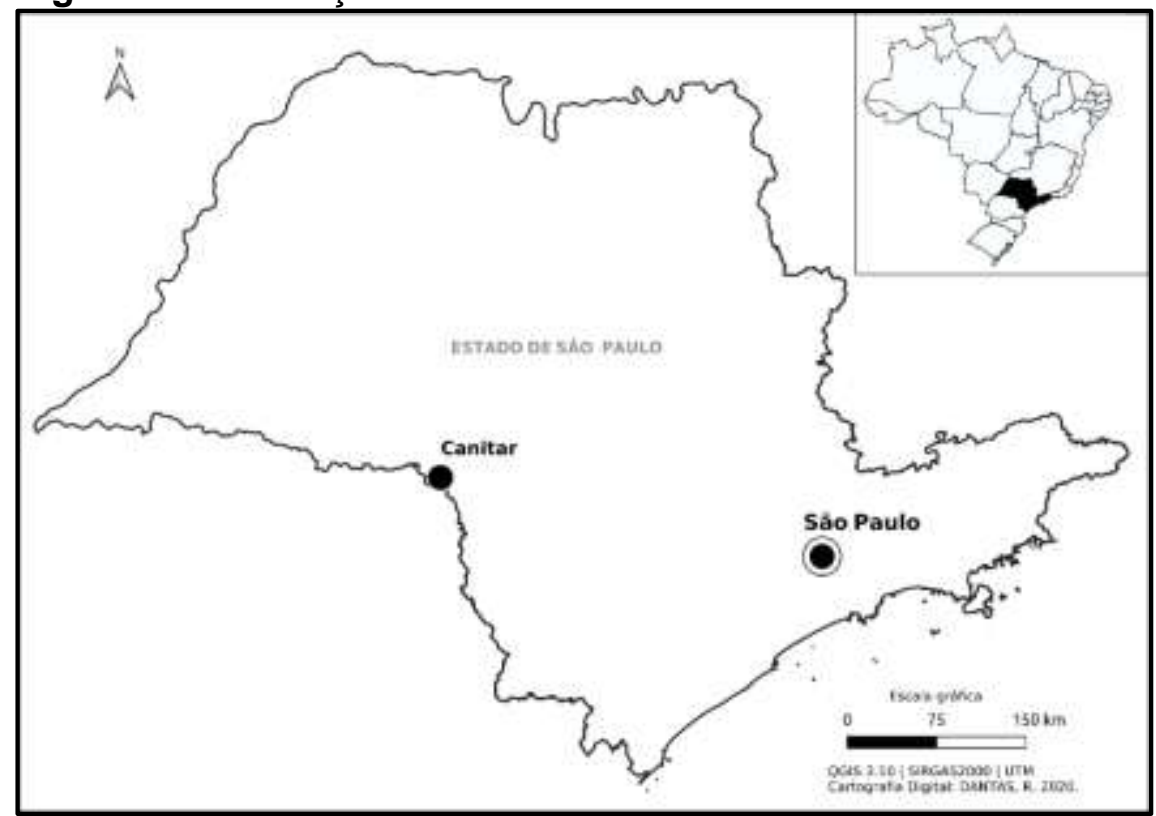

Fonte: organizado pela autora.

Do ponto de vista conceitual, discutem-se as pequenas cidades e o agronegócio da cana-de-açúcar. Não há consenso sobre o que seria uma pequena cidade, embora duas perspectivas teórico-metodológicas sobressaiam-se: 1) O papel na rede urbana; 2) O tamanho populacional. O papel na rede urbana pauta-se na análise das interações econômicas que esse escalão urbano desenvolve em relação aos outros centros urbanos da rede urbana, sendo limitado ao nível imediatamente superior. As pequenas cidades equivalem aos centros de zona e centros locais. Quanto ao aspecto populacional, parcela dos pesquisadores considera que o limite de 50.000 habitantes caracteriza a pequena cidade. Do ponto de vista demográfico, Canitar é uma pequena cidade caracterizada por sua população diminuta e, quanto à rede urbana, é um centro local vinculado à rede urbana de Ourinhos, não exercendo influência sobre nenhum outro núcleo urbano (IBGE, 2020b).

A metodologia consistiu em fontes primárias e secundárias. As fontes primárias referem-se aos levantamentos de campo em junho de 2017 e 2018, quanto aos elementos relativos à economia e aspectos sociais de Canitar, através de entrevistas e registro fotográfico. As fontes secundárias foram a revisão bibliográfica e os dados estatísticos. 


\section{PEQUENAS CIDADES: ALGUMAS CONSIDERAÇÕES CONCEITUAIS}

No último quartel do século $X X$, a complexificação do processo de acumulação capitalista e seus desdobramentos, revelados nas mudanças na divisão territorial do trabalho, levaram à desconcentração de algumas indústrias, serviços e o crescimento do agronegócio, trazendo transformações às pequenas cidades e gerando o interesse de alguns pesquisadores pelo estudo dessas cidades. Assim, o ideário de que as pequenas cidades são lugares marcados pela imutabilidade econômica e social tem sido cada vez mais questionado.

O aspecto populacional coloca-se na perspectiva de compreender uma das características das pequenas cidades, a quantidade diminuta. Para o Instituto Brasileiro de Geografia e Estatística - IBGE, a cidade é um agrupamento humano que apresenta características urbanas, sendo considerado pelo mesmo órgão governamental para fins estatísticos, não fixando um número mínimo de habitantes, porém estipulando o limite de 50.000 habitantes (IBGE, 2020b), sendo que o Instituto de Pesquisa Econômica Aplicada (2000) utiliza o mesmo número. Corrêa (2006) também considera que a população até 50.000 habitantes caracteriza a pequena cidade, porém há autores que apontam limites bastante superiores, caso de Amorim Filho e Serra (2001) para os quais a pequena cidade não ultrapassa 100.000 habitantes. Para Veiga (2002), a pequena cidade não excede o tamanho populacional de 20.000 habitantes, enquanto Oliveira e Soares (2002) consideram a população entre 2.000 e 20.000 habitantes como relativa às pequenas cidades.

A outra perspectiva do entendimento do significado das pequenas cidades, embora não exclua o aspecto populacional, diz respeito ao papel na rede urbana. Conforme Endlich (2006) o fator populacional é incompleto para identificar-se uma cidade como pequena. Para a autora, mediante distintas realidades encontradas no contexto brasileiro, há aquelas redes urbanas com a ausência das cidades de porte médio, sendo compostas por pequenas cidades e pela presença de uma grande cidade, em geral a capital do estado, e, nesse caso, é possível que existam relações hierárquicas entre as pequenas cidades.

Do mesmo modo, Fresca (2010) considera que o fator populacional é incompleto para compreender as pequenas cidades, na medida em que algumas têm um limite mínimo de complexidade de atividades urbanas e outras têm funções urbanas mais complexas. Portanto, é preciso entender como ocorre a inserção da pequena cidade na rede urbana ou região, no contexto socioeconômico, a fim de não igualar cidades com populações análogas, mas que apresentam características sociais e econômicas diferentes.

Para Corrêa (2011) a pequena cidade é um núcleo de povoamento onde parte da população trabalha em atividades ligadas à transformação, circulação de mercadorias e 
prestação de serviços. Pressupõe uma elementar divisão territorial do trabalho, apoiada na existência de atividades que atendam às necessidades mínimas da população. Para o autor, trata-se de centros urbanos que ocupam os níveis hierárquicos menos relevantes na rede urbana, cujas funcionalidades são bastante limitadas e a área de influência é muito restrita.

Quanto a rede urbana, destaca-se a contribuição de Milton Santos (2014), procurando analisar conceitualmente e articular o território. Outro viés importante apresentado pelo autor é teoria dos circuitos superior e inferior da economia, auxiliando as análises sobre a rede urbana brasileira (SANTOS, 2004). Para o autor, a rede urbana é resultado de um equilíbrio de massas e fluxos, com mudanças quanto à concentração e dispersão, ocasionando o domínio dos espaços a partir das aglomerações (SANTOS, 2008).

\section{A PEQUENA CIDADE DO AGRONEGÓcIO DA CANA-DE-AÇÚCAR}

Conforme Corrêa (2011), a partir da década de 1960 as pequenas cidades passaram por mudanças na divisão territorial do trabalho, desencadeadas pelo processo de modernização agrícola, industrialização das atividades agropecuárias e concentração fundiária, resultando na refuncionalização urbana. Com isso, presentemente há distintos padrões funcionais: 1) pequenas cidades submetidas à agricultura capitalista; 2) pequenas cidades funcionalmente especializadas em alguma atividade industrial; 3) pequenas cidades transformadas em cidades-dormitórios, cuja contiguidade é atrelada às cidades expressivas, do ponto de vista econômico; 4) pequenas cidades que concentram trabalhadores que atuavam no campo, porém perderam seus empregos em decorrência da modernização agrícola e da concentração fundiária; 5) pequenas cidades esvaziadas do ponto de vista demográfico e que dependem de recursos econômicos externos.

Canitar refere-se à pequena cidade submetida à agricultura capitalista devido ao cultivo de cana-de-açúcar e disponibilização de mão-de-obra para o setor. Nas palavras de Corrêa (2011, p. 11), essas cidades são "[...] lugar central de uma hinterlândia agrária moderna, capitalista. Este lugar central deve ser considerado como parte integrante do Complexo Agroindustrial, reflexo, meio e condição deste quadro geográfico".

O termo agronegócio, oriundo do agrobusiness americano, foi difundido a partir da década de 1980, associado à mecanização e racionalidade do processo produtivo (DELGADO, 2000). O agronegócio realiza-se a partir de cadeias produtivas, sendo que, no caso da cana-de-açúcar, objetiva-se a obtenção das commodities açúcar e etanol, por meio de processamento industrial. A cadeia produtiva da cana-de-açúcar é composta do plantio, processamento industrial, transformação nas commodities e escoamento da produção.

O cultivo da cana-de-açúcar ocorre desde o período colonial, mas a implementação do Proálcool em 1975 (BRASIL,1975), associado à modernização da agricultura, contribuiu 
para a expansão do cultivo em diversas partes do território brasileiro. Em 2015 a cana-deaçúcar tornou-se o principal cultivo que origina commodities, em quantidade produzida, com 754,9 milhões de toneladas, sendo que o cultivo compreende 3.276 municípios (IBGE, 2017b).

Apesar desse crescimento, os empregos no setor canavieiro têm diminuído, sobretudo quanto ao cultivo. Os motivos são o processo de modernização produtiva e a lei no 11.241/2002 (SÃO PAULO, 2002), a qual estipulava que até o fim do século XX extinguir-seia a despalha por queima, diminuindo a quantidade de trabalhadores boias-frias contratados. Em 2017, a mecanização no estado de São Paulo era 98\%, sendo o trabalho do boia-fria necessário apenas nas áreas mais íngremes, com inclinação superior a 12ํ (IBGE, 2017b).

Em decorrência da impossibilidade do armazenamento da cana-de-açúcar há a necessidade de canaviais próximos à unidade de processamento. Portanto, onde se produz cana-de-açúcar, geralmente há alguma agroindústria nas proximidades. Assim, as áreas produtoras distam até 50 quilômetros da agroindústria, embora as maiores agroindústrias quanto a capacidade produtiva possam receber cana-de-açúcar de até 150 quilômetros de distância, o que pode abranger vários municípios. Essas áreas produtoras referem-se à estabelecimentos rurais da própria agroindústria ou arrendados.

O processamento industrial da cana-de-açúcar ocorre nas agroindústrias e a logística de escoamento dos derivados difere substancialmente. No caso do etanol hidratado a produção é direcionada principalmente para o mercado interno, atendendo a demanda quanto a indústria química, alcoolquímica, supermercados, comércio varejistas e principalmente a indústria petroquímica. Quanto ao açúcar, a alimentação brasileira é fortemente pautada nesse item, sendo que nas últimas décadas cresceu a demanda, embora não esteja relacionada ao açúcar ensacado, mas quanto a inserção em alimentos industrializados. Por outro lado, o Brasil é o maior exportador mundial de açúcar (IBGE, 2017b).

Mediante o breve quadro exposto acerca da cadeia produtiva da cana-de-açúcar, compreende-se que há interações econômicas que extrapolam a escala local. A gestão produtiva, escoamento e comercialização dos derivados da cana-de-açúcar encontram-se localizadas em cidades de grande e médio porte, e, em alguns casos, em outros países, pois as commodities possuem demanda global. Os serviços relativos à manutenção de maquinários utilizados nas agroindústrias, comercialização de fertilizantes, escritórios de contabilidade, advocacia e agências bancárias, entre outros, serão encontrados nas cidades de médio porte, próximas às agroindústrias processadoras. A pequena cidade porta-se como reservatório de mão-de-obra para a etapa do cultivo, embora a demanda seja cada 
vez menor, frente à mecanização da colheita e em relação à agroindústria processadora, cujos empregos exigem qualificação profissional.

\section{CANITAR E O AGRONEGÓCIO DA CANA-DE-AÇÚCAR}

Canitar, cuja origem liga-se ao município de Chavantes - SP, manteve-se como distrito até 1991, quando ocorreu sua emancipação. Porém, a gênese refere-se à fazenda Fortuna, onde cultivava-se café, sendo que, em 1923, inaugurou-se um ramal da ferrovia Sorocabana, facilitando o escoamento da produção cafeeira local, favorecendo o desenvolvimento de um núcleo urbano o qual tornou-se posteriormente Canitar.

Canitar, com área municipal de 57,38 quilômetros quadrados (ou 5.738 hectares) é um pequeno município do ponto de vista territorial, cuja cana-de-açúcar é predominante, na medida em que 4.429 hectares são ocupados por esse cultivo e não há outra atividade agropecuária relevante. Canitar não figura entre os principais produtores brasileiros de canade-açúcar, a área ocupada é relevante apenas em comparação à área municipal e a produção não é suficiente para o abastecimento de uma agroindústria processadora de maior porte, porém mostra-se a principal atividade econômica municipal, com desdobramentos no espaço urbano. Em termos comparativos, Canitar figura apenas como o $607^{\circ}$ maior produtor brasileiro de cana-de-açúcar e 355 no estado de São Paulo, sendo que o município de Monte Alto - SP lidera esse quesito tanto no âmbito estadual quanto nacional, como uma produção de 8.118 .000 toneladas. O mesmo ocorre com a área cultivada, liderada por Monte Alto com 99.000 hectares (IBGE, 2017a).

Trata-se de uma pequena cidade, na medida que no censo de 2010 (IBGE, 2010), havia 4.369 habitantes, dos quais 231 eram rurais e 4.128 urbanos, refletindo uma taxa de urbanização de $94,71 \%$. Portanto, Canitar configura-se como uma pequena cidade, sede de um município igualmente pequeno, cuja área rural é ocupada principalmente pelo cultivo da cana-de-açúcar, sendo que na figura 2 observa-se que o cultivo abrange áreas bastante próximas ao perímetro urbano:

Associado ao predomínio do cultivo de cana-de-açúcar e à população majoritariamente urbana há a concentração de terras, conforme se nota na tabela 1. Há apenas 32 estabelecimentos rurais, e, embora os estabelecimentos com menos de 10 hectares sejam prevalentes (16), os mesmos ocupam 83 hectares ou 1,61\% da área relativa aos estabelecimentos rurais. Há 14 estabelecimentos com tamanho entre 10 e 50 hectares, somando a área de 399 hectares ou 7,76\% e 1 estabelecimento com área de 500 hectares, o qual ocupa $9,73 \%$ da área total. Porém a concentração de terras refere-se ao estabelecimento rural que soma 4.154 hectares, ou $80,88 \%$ da área total, onde o cultivo de 
cana-de-açúcar ocorre mediante o arrendamento da terra, comercializado com a Usina São Luiz.

Figura 2 - Cultivo de cana-de-açúcar próximo à rua 6, perímetro urbano de Canitar

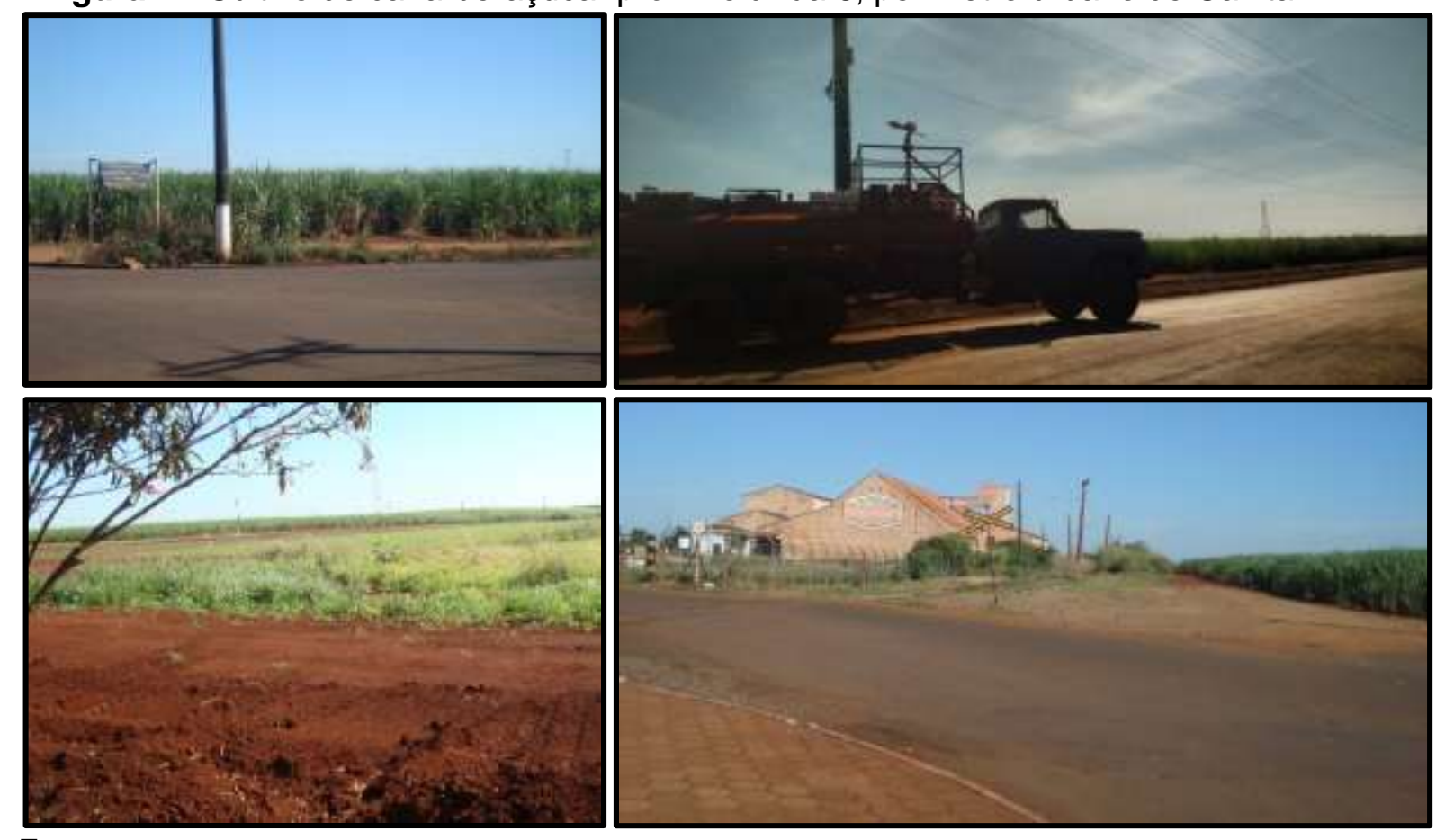

Fonte: autora.

Tabela 01 - Quantidade e área dos estabelecimentos rurais quanto à estrutura dimensional, em Canitar, 2017

\begin{tabular}{c|c|c|c|c}
\hline Grupos de área & $\mathrm{n}^{\mathbf{0}}$ & $\%$ & Área (ha) & $\%$ \\
\hline Menos de 10 & 16 & $51,61 \%$ & 83 & $1,61 \%$ \\
10 a 50 & 14 & $43,40 \%$ & 399 & $7,76 \%$ \\
51 a 100 & 0 & 0 & 0 & 0 \\
101 a 500 & 1 & $3,22 \%$ & 500 & $9,73 \%$ \\
501 a 1.000 & 0 & 0 & 0 & 0 \\
Mais de 1.000 & 1 & $3,22 \%$ & 4.154 & $80,88 \%$ \\
\hline Total & \multicolumn{2}{|c}{31} & \multicolumn{2}{c}{5.136} \\
\hline
\end{tabular}

Fonte: elaboração própria com base nos dados do IBGE (2017a).

Os latossolos e argissolos, presentes no município, associados ao tipo climático tropical de altitude (inverno seco e verão quente), com temperaturas mínimas entre $16^{\circ} \mathrm{C} \mathrm{e}$ $30^{\circ}$ C máximas e geadas pouco frequentes, facilitaram a expansão e consolidação da canavicultura (SELANI, 2005). A cana-de-açúcar foi inserida no município em meados da década de 1970, no contexto da expansão canavieira resultante do Proálcool, a partir da ação da família Quagliato, proprietária da Usina São Luiz de Ourinhos. Nesse período, Canitar, que ainda era um distrito de Chavantes, passou por um processo de substituição do café pela cana-de-açúcar. Na década seguinte foi inaugurada em Canitar a Destilaria Ponte Preta, contribuindo para a consolidação do setor canavieiro no município. Porém, em 1999 
as atividades da destilaria encerraram-se, sendo que em 2007 um grupo de acionistas americanos adquiriu a destilaria, retomando as atividades em 2008. A nova usina de Canitar pertence ao grupo Comanche e possui outras unidades em Simões Filho (BA), Tatuí (SP) e Paulínia (SP).

A Usina São Luiz adquire cana-de-açúcar de estabelecimentos próprios em Ourinhos, Santa Cruz do Rio Pardo e São Pedro do Turvo, e arrendados em Canitar, Chavantes, Salto Grande lbirarema, Ribeirão do Sul e Ipaussu. O percentual de cana-de-açúcar oriundo de estabelecimentos que não pertencem à Usina São Luiz é bastante variável, sendo influenciado por fatores climáticos, condições do solo, preço da matéria-prima, etc.

A Comanche opera em sistema de Spot, isto é, contratos a curto prazo, com destinos variáveis da produção. A empresa não possui estabelecimentos rurais próprios, obtendo matéria-prima de fornecedores diversos, a partir dos sistemas "cana-cana", no qual a Comanche coleta a matéria-prima e escoa até a agroindústria e o sistema "cana-esteira", no qual o fornecedor se encarrega de trazer a matéria-prima.

A Usina Comanche encontrava-se com nível de atividade baixo, e havia iniciado um processo de falência, devido a problemas de gestão. Não empregava, formalmente, nenhum trabalhador oriundo de Canitar, sendo que as contratações eram esporádicas e relacionadas ao período de safra. Não há programas de qualificação profissional local, investimentos em pesquisa e melhoramentos genéticos e variedade na produção de derivados da cana-deaçúcar, na medida em que a produção se restringe ao etanol hidratado. Durante a entressafra não há venda de etanol, pois a empresa não possui reservatório, e, por outro lado, apresenta pequena capacidade de moagem, 1, 2 milhão de toneladas por safra, ou 6.000 toneladas diárias. As atividades executadas pela empresa referem-se à moagem da cana-de-açúcar e produção de etanol, cujo escoamento é realizado por terceiros.

A Usina São Luiz emprega cerca de 4.000 trabalhadores, sendo que 2.300 residem em Ourinhos, 300 em Canitar e os demais em Santa Cruz do Rio Pardo, Chavantes, Ipaussu, Ibirarema, Salto Grande e São Pedro do Turvo. Durante a safra são contratados 200 trabalhadores adicionais. O setor administrativo e os cargos de gestão são ocupados por trabalhadores residentes em Ourinhos e os trabalhadores de Canitar atuam no setor industrial, serviços de manutenção, fiscalização e nos serviços rurais. O regime de trabalho é regido pela Consolidação das Leis Trabalhistas - CLT. Mediante ao processo de falência da Comanche, a Usina São Luiz se mantem como o maior empregador de Canitar.

Essa divisão do trabalho atrela-se à qualificação profissional, sendo que na cidade de Ourinhos há cursos voltados ao setor (quadro 1), e em Canitar não há oferta, pois o município conta apenas com o ensino fundamental e médio, a partir da E.E. Aparecido Gonçalves Lemos (Médio e EJA - Ensino de Jovens e Adultos) e EMEF Alcino Leite (Fundamental I e II). 
Quadro 1 - Cursos de qualificação profissional atrelados ao setor sucroalcoleiro em Ourinhos

\begin{tabular}{|c|c|c|}
\hline Instituição de Ensino & Ensino Técnico & Ensino Superior \\
\hline Etec Jacintho Ferreira de Sá & $\begin{array}{l}\text {-segurança do trabalho } \\
\text {-açúcar e álcool } \\
\text { - secretariado } \\
\text { - recursos humanos } \\
\text { - química } \\
\text { - informática } \\
\text { - finanças } \\
\text { - contabilidade } \\
\text { - automação industrial }\end{array}$ & $\begin{array}{ll}------ \\
--1\end{array}$ \\
\hline $\begin{array}{c}\text { Senai (Serviço Nacional de } \\
\text { Aprendizagem Industrial) }\end{array}$ & $\begin{array}{l}\text { - técnico de logística } \\
\text { - técnico de eletromecânica } \\
\text { - técnico de informática } \\
\text { - eletricista industrial } \\
\text { - mecânico de usinagem } \\
\text { - caldeireiro }\end{array}$ & ------- \\
\hline $\begin{array}{l}\text { FATEC - Faculdade de } \\
\text { Tecnologia de São Paulo }\end{array}$ & ------ & $\begin{array}{c}\text { - agronegócio } \\
\text { - análise de sistemas } \\
\text { - segurança da informação }\end{array}$ \\
\hline $\begin{array}{c}\text { UniFio - Centro Universitário } \\
\text { Faculdades Integradas de } \\
\text { Ourinhos }\end{array}$ & ------- & $\begin{array}{c}\text {-agronomia } \\
\text { - engenharia mecânica } \\
\text { - engenharia de produção } \\
\text { - administração } \\
\text { - ciências biológicas } \\
\text { - ciências contábeis }\end{array}$ \\
\hline Faculdade Estácio de Sá & $\begin{array}{ll}------ \\
\end{array}$ & $\begin{array}{c}\text {-administração } \\
\text {-engenharia de produção } \\
\text {-gestão de recursos humanos }\end{array}$ \\
\hline
\end{tabular}

Fonte: a autora

Conforme a trabalhadora da Usina São Luiz Juliana Souza (utilizou-se nomes fictícios, pois os agentes sociais entrevistados nessa pesquisa solicitaram sigilo da identidade, alegando receio de perder o emprego), a falta de opções de qualificação profissional em Canitar é um entrave para "arrumar" um emprego ou "subir de cargo" na Usina São Luiz, pois é necessário deslocar-se até Ourinhos, sendo que a prefeitura municipal de Canitar não paga integralmente os custos com transporte. Há ainda o problema referente às mensalidades dos cursos, no caso do SENAI e das faculdades Estácio de Sá e UniFio, em razão da baixa renda da população de Canitar. Esses cursos foram apontados pelo funcionário do setor administrativo da Usina São Luiz, Paulo Santos, como necessários em funções na agroindústria, no setor de finanças e administrativo.

Os serviços rurais foram descritos pelas trabalhadoras Juliana Souza e Maria Ribeiro como um trabalho manual, sem necessidade de qualificação profissional. Consiste em equipes de controle de pragas, formadas por três grupos de 18, 11 e 13 pessoas cada, constituídos majoritariamente por mulheres residentes em Canitar. A remuneração é composta de 1 salário-mínimo acrescido de bonificação por assiduidade. É disponibilizado transporte entre Canitar e a Usina São Luiz e alimentação no refeitório da empresa. 
A função pauta-se no controle de pragas na raiz da cana-de-açúcar, aplicando veneno em formigas, monitorando a qualidade das plantas, mediante à inspeção dos "tocos" da planta a partir da inserção de buracos nos canteiros, sendo dois a cada hectare. A entrevistada Juliana Souza relatou que se trata de um trabalho muito pesado e minucioso, pois é necessário identificar se há a presença de pragas e as respectivas espécies. Outras atividades desempenhadas pelas equipes referem-se a plantar cana-de-açúcar em viveiros destinados às pesquisas realizadas no laboratório da usina, encontrar palhas na roça, medir e tirar fotos das mesmas e de outros elementos nocivos que existam nos canaviais.

Em relação aos trabalhadores boias-frias, o funcionário da Usina São Luiz, Paulo Santos, apontou a diminuição das atividades dos trabalhadores a partir de 2010, em cumprimento à legislação pertinente ao fim da queima por despalha. O entrevistado afirmou que ainda há alguns trabalhos ocasionais, porém não soube quantificar com exatidão quantos trabalhadores exerciam funções manuais e se os mesmos ocorreriam na ocasião do plantio e/ou colheita, pois se tratam de trabalhadores contratados por fornecedores de matéria-prima, não apresentando vínculo com a Usina São Luiz. Porém, o fluxo de trabalhadores sazonais oriundos principalmente dos estados do Maranhão e Minas Gerais extinguiu-se após o ano de 2010, o que coincide com a expansão da mecanização e fim da queima por despalha, sendo que os empregos que são criados são ocupados por boias-frias locais

O representante da Usina São Luiz relatou que os boias-frias que trabalhavam nas propriedades da empresa não estavam mais "aguentando o trabalho", referindo-se à atividade extenuante do corte da cana-de-açúcar e se aposentaram ou "encostaram pelo INSS". Já as trabalhadoras Juliana e Maria relataram que os ex-boias-frias que não conseguiriam outro trabalho ou se aposentaram ou passaram a depender de "ajuda do governo", citando o programa Bolsa Família. Em consulta ao Portal da Transparência verificou-se que 2018 havia 347 pessoas em Canitar registradas no Bolsa Família ou 8\% da população (BRASIL, 2018).

A Usina São Luiz apresenta cargos de chefia, supervisão dos distintos setores da agroindústria e dos serviços desempenhados na parte rural, funções administrativas e de pesquisa e operador de colheitadeira, sendo esses os melhor remunerados. Porém, a maioria dos trabalhadores está submetida ao teto de $R \$ 2.000$ para tratoristas, operadores de máquinas agrícolas e coordenadores do setor industrial em geral. Os demais trabalhadores, como o controle de pragas, segurança, operários da agroindústria e dos serviços de apoio (restaurante, limpeza e escritório) recebem um salário-mínimo acrescido de bonificação por assiduidade. Situação semelhante foi verificada na Usina Comanche, porém com o diferencial da ausência da alimentação disponibilizada pela empresa, auxíliosaúde e odontológico. 
Ligado ao setor canavieiro, há em Canitar a indústria de fertilizantes Fertipar, empresa de capital não-local, que gera 30 empregos, sendo que maioria dos trabalhadores residem na cidade, com exceção dos cargos de gerência e supervisão, cujos trabalhadores residem em Ourinhos. Os fertilizantes são vendidos em municípios de maior porte, sendo direcionados a diferentes cultivos, destacando-se a cana-de-açúcar. Não há em Canitar comércio de produtos agrícolas e a Fertipar é a única indústria da cidade.

\section{CANITAR, A PEQUENA CIDADE DA CANA-DE-AÇÚCAR}

No âmbito urbano, excetuando-se a fábrica de fertilizantes, a cidade não apresenta outras atividades atreladas ao agronegócio da cana-de-açúcar. Não há cursos voltados à qualificação profissional, empresas prestadoras de serviço no setor canavieiro, escritórios de profissionais liberais necessários a efetivação do agronegócio (advogados, engenheiros agrônomos, engenheiros de materiais, etc.), concentrando-se tais funções em Ourinhos.

Excetuando-se os empregos gerados pela Usina São Luiz, há pouca oferta de vagas em Canitar. Por esse motivo, há a denominada frente de trabalho, cujas atividades são remuneradas pela prefeitura municipal de Canitar e referem-se a coleta de lixo, coleta seletiva de lixo doméstico, apoio em limpeza e preparação de refeições em escolas, com remunerações de meio salário-mínimo. Empregos temporários são opções aos habitantes de Canitar, caso das funções referentes à duplicação e pavimentação da rodovia Raposo Tavares, entre o km 295,4 até o km 373, entre os anos de 2017 e 2018, promovida pela S/A Asfaltos, gerando 100 empregos com remuneração de 1 salário-mínimo.

A prefeitura municipal de Canitar é um importante empregador, embora a oferta de empregos melhor remunerados seja pequena e restrita aos cargos que exigem nível superior. Os cargos de dentista, enfermeiro, farmacêutico, psicólogo, fisioterapeuta e assistente social, cuja jornada de trabalho é de 30 horas, referem-se ao salário de $R \$$ $1.800,00$. Porém, conforme o funcionário da prefeitura municipal, Marcio Lopes, a maioria dos empregos exige nível fundamental e apresentam a remuneração de um salário-mínimo. Os cargos de nível médio como auxiliar de enfermagem, telefonista e escriturário têm remuneração de $\mathrm{R} \$ 1.300$.

Outro setor que oferece empregos em Canitar, a educação, emprega professores de educação básica de anos finais - PEB II, cuja remuneração por 30 horas é em média $\mathrm{R} \$ 1.600$ e professores de educação básica de anos iniciais - PEB I, cujos profissionais recebem a mesma remuneração, porém referente a 40 horas semanais. No caso do ensino médio e Ensino de Jovens e Adultos - EJA, o salário médio é $\mathrm{R} \$ 2.000$, por 40 horas semanais. Porém, conforme Claudia Silva, funcionária de um estabelecimento de ensino de 
Canitar, a maioria desses professores não reside na cidade, sendo oriundos de Chavantes e Ourinhos. Há ainda os empregos de assistente de alfabetização, cuja remuneração é de $\mathrm{R} \$$ 750 por 25 horas semanais e os cargos de nível médio, inspetor de aluno e secretário de escola, com salário de 1.300 reais por 40 horas de trabalho.

Mediante os baixos salários citados e a falta de opções de emprego, Canitar destacase negativamente por apresentar o IDH municipal de 0,68, um dos piores do estado de São Paulo. Os resultados expressam-se nas residências, sendo que aquelas construídas de alvenaria são bastante simples e parcela, principalmente na área central, são de madeira, conforme se observa na figura 3 . Esses resultados também se expressam quanto à dificuldade que a prefeitura municipal apresenta na manutenção da infraestrutura urbana, conforme se observa na figura 4. Na figura 4 observa-se o Auto Posto Canitar, único no segmento e que atende principalmente caminhoneiros não residentes em Canitar, na medida que a entrevistada Juliana afirmou ser "mais barato" abastecer em Ourinhos.

Figura 3 - Residências localizadas no Centro de Canitar

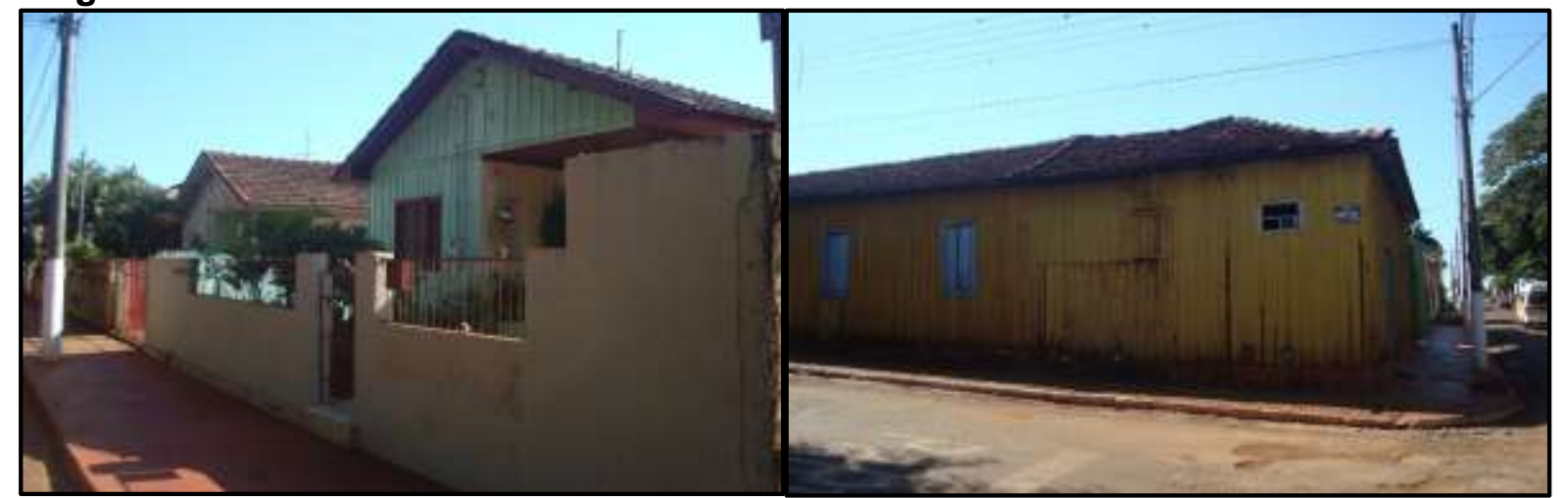

Fonte: autora.

Figura 4 - Vista parcial de algumas ruas de Canitar

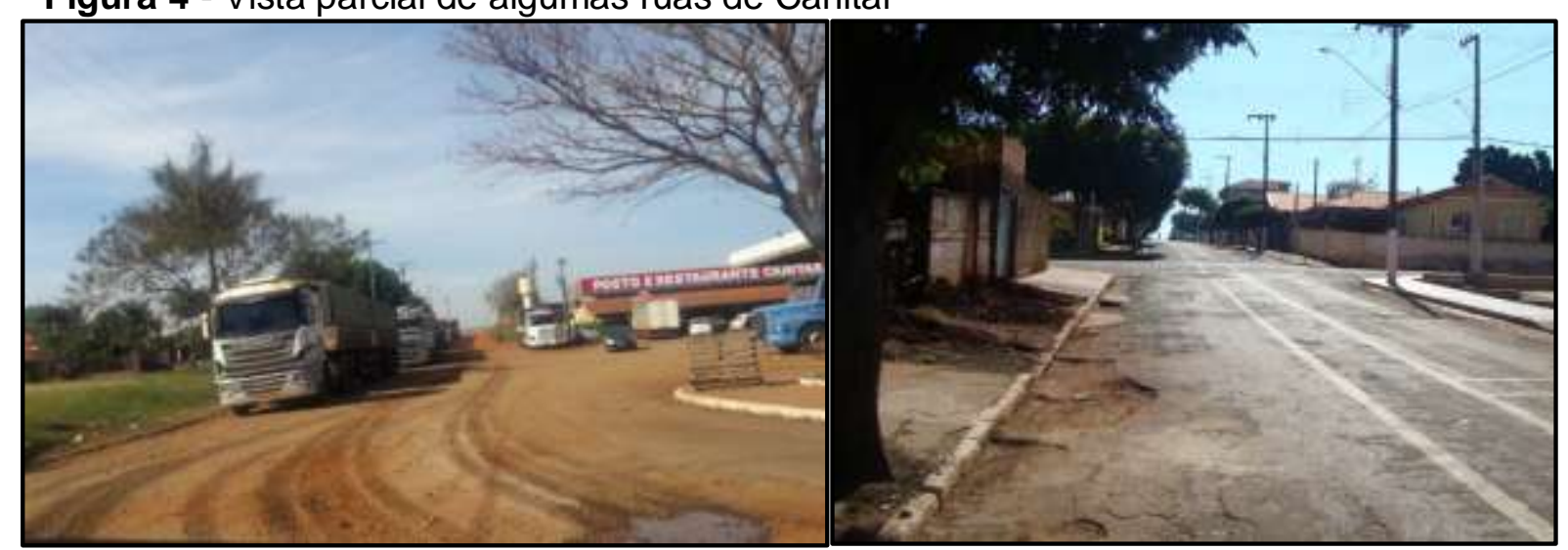

Fonte: autora.

Os resultados são observados também nas atividades econômicas urbanas, denotando dependência do poder público quanto ao acesso aos serviços, infraestrutura e 
assistência social. A iniciativa privada, quanto à oferta de comércio e serviços, é restrita, sendo necessário o deslocamento até Ourinhos, quanto ao acesso a serviços e comércio mais diversificados.

Apesar da inauguração da rodoviária municipal (figura 5), em 2017, a mesma não está funcionando e apenas uma empresa de ônibus opera na cidade, a Manoel Rodrigues/SA, disponibilizando a linha Santa Cruz do Rio Pardo - Ourinhos. Há apenas um itinerário, perpassando a principal rua de Canitar (figura 5), com intervalos de uma hora durante a semana e de duas horas em fins de semana e feriados, ligando Canitar à Santa Cruz do Rio Pardo (35 quilômetros) e Ourinhos (7 quilômetros). Devido ao fato de a rodoviária municipal não estar em funcionamento, a linha de ônibus da empresa Manoel Rodrigues / SA e as "vans" utilizam o ponto localizado na mesma rua (figura 5).

Figura 5 - Rodoviária de Canitar e ponto de ônibus, rua Joaquim Bernardes Mesquita

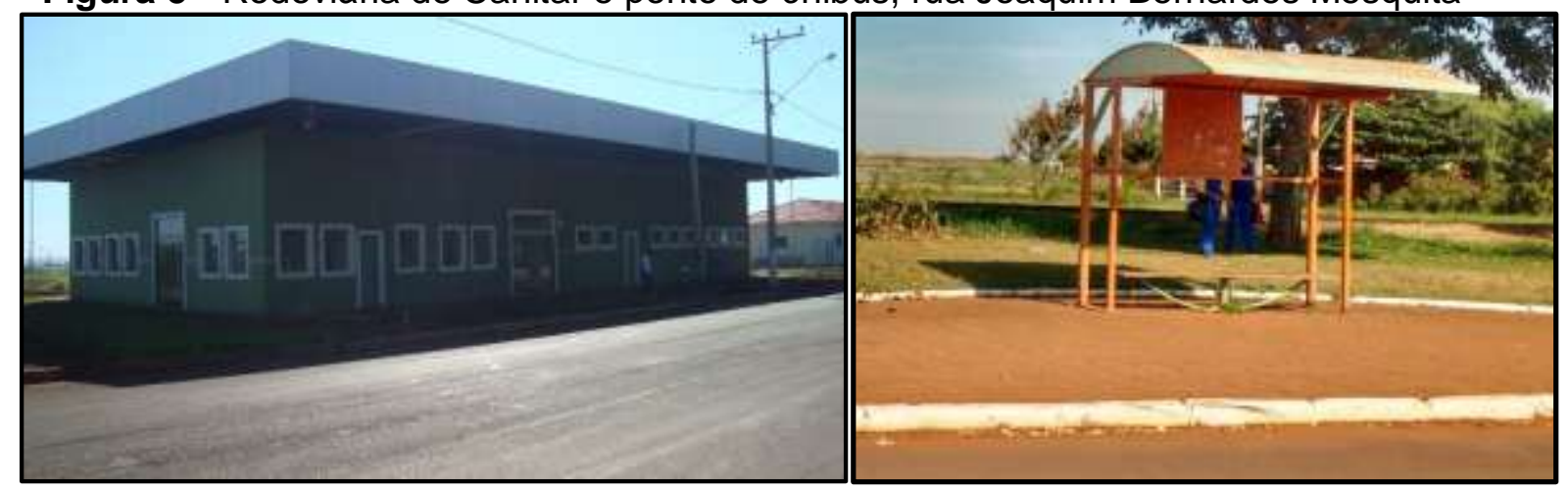

Fonte: autora.

A falta de opções de transporte culminou com a existência de "vans" que fazem o trajeto entre Canitar (Centro) e Ourinhos - Hospital Santa Casa de Misericórdia e Centro, com horários cujos intervalos variam de meia hora a uma hora, dependendo da "demanda", conforme informou Carlos Lima, um motorista entrevistado. Não há ponto de taxi, nem serviço de aplicativo operando na cidade, embora esse serviço seja prestado de forma informal.

No âmbito da saúde, há um posto de saúde e um ambulatório médico, não existindo consultório médico ou odontológico particular, laboratório de análises clínicas, nem hospital, sendo que as demandas médicas de maior complexidade e emergências são encaminhadas para Ourinhos. Não há estabelecimento educacional de ensino privado, faculdade, escola de informática ou línguas estrangeiras. Não há fórum, corpo de bombeiros e o funcionamento da delegacia da polícia militar ocorre em sistema de plantão. A prefeitura municipal atua como geradora de empregos e atende as demandas da população.

Em relação ao setor bancário, há apenas uma agência bancária, do banco Bradesco, uma lotérica e a agência dos Correios, onde funciona um banco postal do Banco do Brasil 
(figura 6), sendo que o acesso as demais agências bancárias ocorre em Ourinhos (Banco do Brasil, Caixa Econômica Federal, Itaú, Santander, Banco Mercantil, Sicredi e BMG) ou Chavantes (Bradesco, Caixa Econômica Federal e Banco do Brasil).

Figura 6 - Estabelecimentos que prestam serviços bancários em Canitar

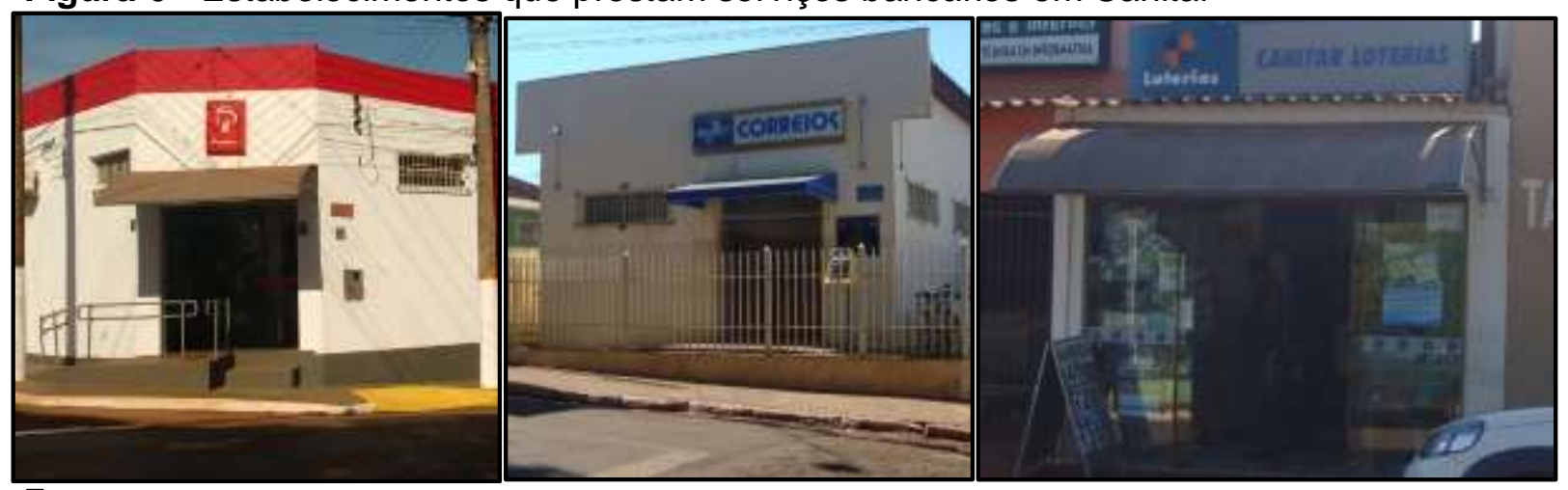

Fonte: autora.

Não há loja de eletrodomésticos, móveis ou outros bens de consumo duráveis. Na inexistência de concessionárias de veículos e de mecânicas autorizadas por fabricantes, encontram-se alguns estabelecimentos que prestam os serviços de conserto dos mais diversos veículos, e, quando há a necessidade de peças, as mesmas são obtidas em Ourinhos. A figura 7 evidencia a pouca complexidade dos serviços oferecidos, sendo que o lava-car e a borracharia são os únicos estabelecimentos desse segmento em Canitar. Os serviços relacionados a estética em geral são prestados em pequenos e simples estabelecimentos (figura 7). Do mesmo modo, nota-se o único estabelecimento que comercializa e presta serviços elétricos para residências e a presença do estabelecimento "Feliciano", que presta serviços imobiliários, advocacia, e realiza empreendimentos imobiliários.

A informalidade é presente no comércio de Canitar, na medida que há os "bazares itinerantes", montados em um espaço pertencente à prefeitura municipal e que atendem à demanda de consumo da população de baixa renda. Canitar apresenta apenas um supermercado, uma farmácia e uma padaria, embora existam diversas "portinhas". As portinhas localizam-se anexas às residências, em geral nas garagens, sendo compostas por uma porta que dá acesso a mesma e uma fachada bastante simples.

Nesses estabelecimentos foram encontrados os seguintes serviços/comércios: venda de marmitex, lanche e bebidas, encomenda de salgados e bolos para festas, barbearia, cabeleireiro e manicure, lan house e xerox, brechó, costureira, bares, loja de roupa, papelaria e assistência técnica em eletrônicos e informática. Há ainda trailers onde são comercializados lanches e petiscos, localizados principalmente nas proximidades da 
prefeitura municipal e da escola E.E. Aparecido Lopes Gimenez. Na figura 8 observam-se as "portinhas" e os estabelecimentos que funcionam como mercearias/bar/conveniência.

Figura 7 - Estabelecimentos prestadores de serviços em Canitar

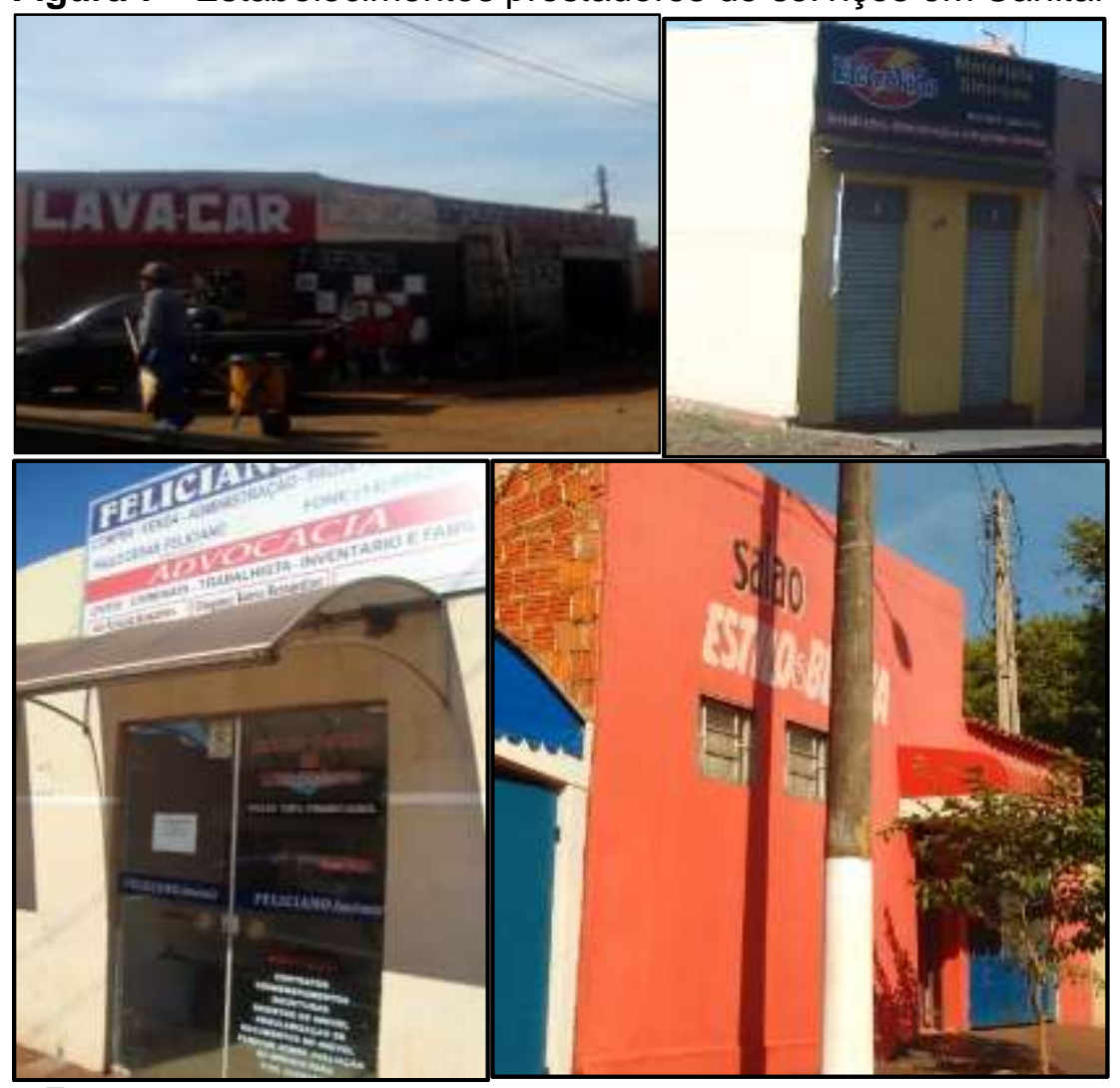

Fonte: autora.

Diante da baixa renda da população local e da debilidade econômica local, observa-se a falta de opções de lazer, sendo que na figura 9 nota-se a praça do Campo 19 de maio com alguns trailers, e as academias ao ar livre, sendo apontadas pelas entrevistadas Juliana e Maria como algumas das poucas opções de lazer na cidade. Ambas citaram as festas realizadas entre familiares e os barzinhos (em portinhas) como opções de lazer noturnas. 
Figura 8 - Estabelecimentos comerciais de Canitar

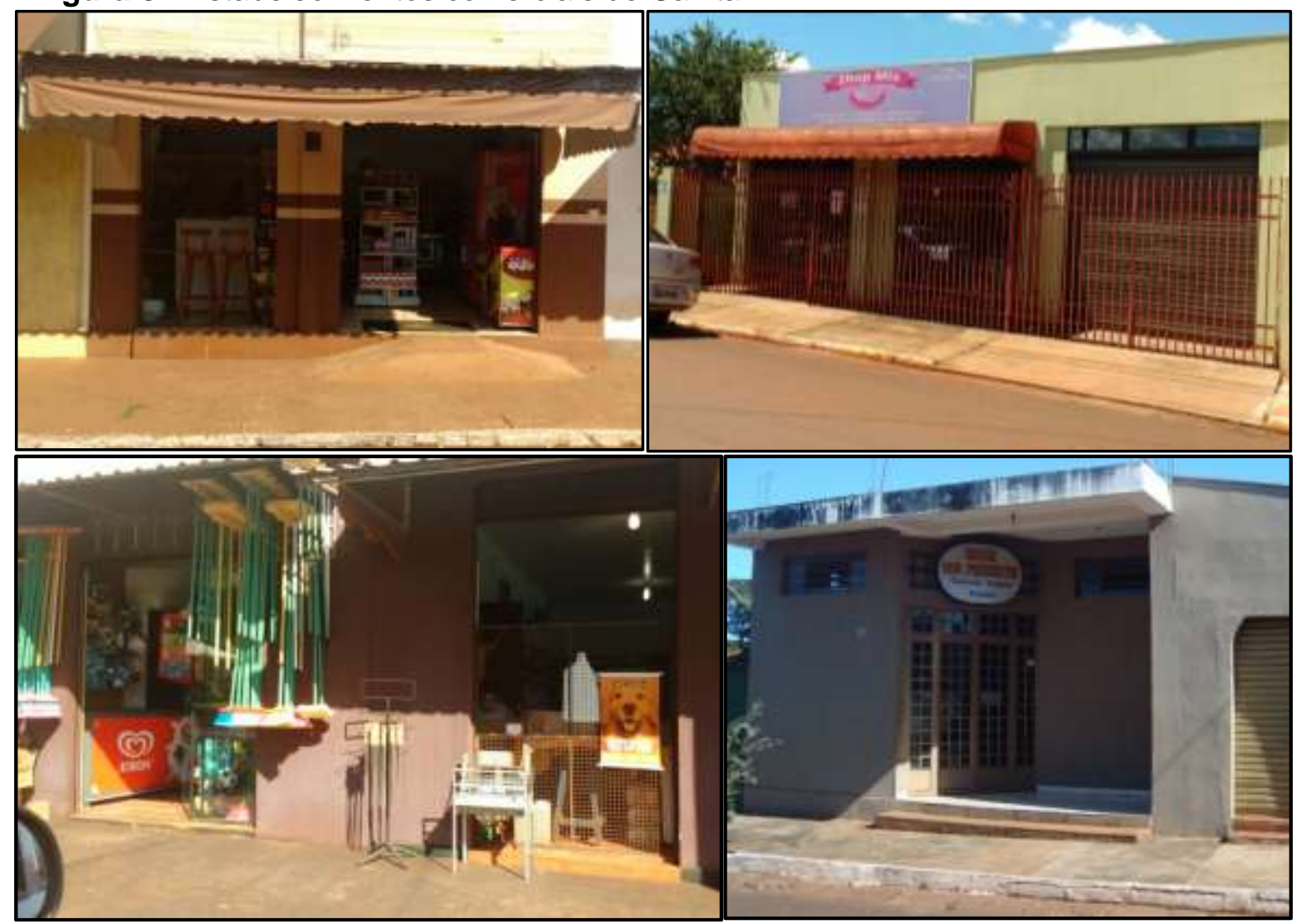

Fonte: autora.

Figura 9 - Praças e academias ao ar livre em Canitar

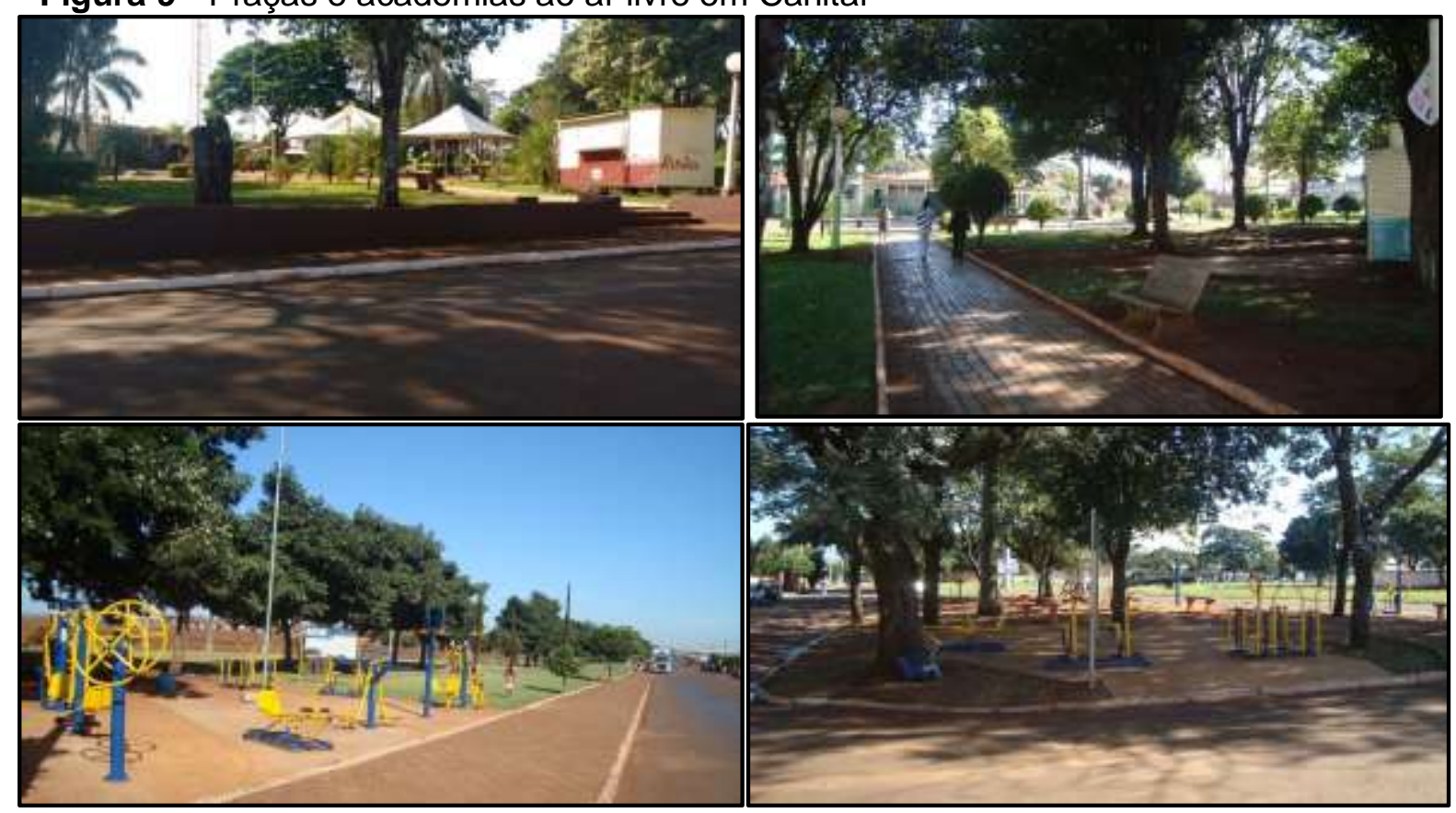

Fonte: autora. 


\section{CONSIDERAÇÕES FINAIS}

Canitar é uma pequena cidade, sede de um município igualmente pequeno, que apresenta sua singularidade quanto à forma como participa da cadeia produtiva da cana-deaçúcar e os seus desdobramentos no espaço urbano. Notabiliza-se pela extensão do cultivo, que abarca quase toda a área municipal, não existindo outras atividades agropecuárias relevantes. O cultivo ocorre em estabelecimentos rurais arrendados, sendo a produção comercializada com a Usina São Luiz de Ourinhos. Tal produção é apenas uma parte da matéria-prima utilizada pela usina citada, embora seja toda a produção agrícola de Canitar. Do mesmo modo a área ocupada pela cana-de-açúcar e a quantidade produzida em Canitar é pouco relevante se comparada com os municípios que se notabilizam por serem os maiores produtores nacionais.

A Usina São Luiz não gera impostos ao município de Canitar, pois localiza-se em outro município e tampouco a cana-de-açúcar é capaz de gerar renda de forma direta à população, na medida que é uma monocultura a partir da qual é possível gerar commodities, cuja demanda é global e na qual é necessário o emprego do processamento industrial, realizado na agroindústria. A Comanche, embora localizada em Canitar, tampouco contribui para a geração de impostos ou empregos, dado o baixo nível da atividade e o processo de falência em curso.

Porém a cana-de-açúcar gera empregos, no âmbito da agroindústria, já que os empregos rurais, outrora realizados pelos boias-frias, encontram-se cada vez mais escassos. Entretanto, os empregos na agroindústria exigem qualificações profissionais as quais os trabalhadores de Canitar, em geral, não têm acesso, pois são obtidas através de cursos na cidade de Ourinhos. Nesse sentido, Canitar porta-se como reservatório de mãode-obra, caso seja necessária, na etapa do cultivo, em especial no período de safra, e nas poucas funções rurais ainda existentes. O outro papel desempenhado por Canitar na cadeia produtiva da cana-de-açúcar é de local onde ocorre a produção dessa monocultura.

Como resultado, Canitar apresenta dependência da ajuda governamental, no tocante ao programa Bolsa Família, que supre parcela da demanda relacionada à falta de emprego ou baixa renda da população, predominante no município. A prefeitura municipal e o governo estadual também são importantes empregadores no município. As outras opções de emprego e/ou geração de renda à população são os empregos temporários, a Frente de Trabalho e o comércio e serviços informais, realizados nas "portinhas". Para os citadinos que não conseguem um emprego formal, sendo parcela constituída por ex boias-frias, resta o auxílio governamental e/ou os empregos temporários. 
Quanto às atividades econômicas urbanas, Canitar não possui um setor industrial destacado, sendo composto apenas pela indústria de fertilizantes Fertipar, e disponibiliza à população apenas serviços básicos na medida em que a falta de lojas e serviços especializados atrela-se diretamente à baixa renda da população local. A proximidade com a cidade de Ourinhos, apenas sete quilômetros, satisfaz a demanda da população com renda mais elevada e que procura por serviços ou itens comerciais mais específicos.

Canitar tem dificuldades para exercer seu papel de cidade, pois não é capaz de suprir as demandas de baixa complexidade, sendo dependente de Ourinhos quanto ao acesso a serviços médicos, formação profissional, comércio varejista com variedade maior, serviços diversos, acesso a transporte para outras localidades, na medida que em Canitar só há ônibus para Ourinhos.

Portanto, Canitar insere-se no caso das pequenas cidades submetidas à agricultura capitalista, mas principalmente no caso das cidades do agronegócio que, de acordo com Elias (2006), apresentam vulnerabilidade econômica latente devido à sua economia dependente de um único setor. Por sua vez, é o elo mais frágil, uma vez que o comando produtivo é em muitos casos exercido a partir de locais distantes, ao passo que a riqueza gerada não é investida na cidade.

\section{REFERÊNCIAS}

AMORIM FILHO, Oswaldo; SERRA, Rodrigo Valente. Evolução e perspectivas do papel das cidades médias no planejamento urbano e regional. In: ANDRADE, Thompson Almeida; SERRA, Rodrigo Valente. (org.) Cidades médias brasileiras. Rio de Janeiro: IPEA, 2001. p. 1-34. Disponível em:

http://repositorio.ipea.gov.br/bitstream/11058/3081/4/Cap_1_evolucao.pdf. Acesso em: 23 jul. 2020.

BRASIL. [Constituição (1988)]. Constituição da República Federativa do Brasil de 1988. Brasília, DF: Presidência da República, 1988. Disponível em:

http://www.planalto.gov.br/ccivil_03/constituicao/constituição.htm. Acesso em: 12 jun. 2020.

BRASIL. Controladoria-geral da União. Portal da Transparência. Bolsa Família.

Controladoria-geral da União. Brasília, DF: CGU, 2018. Disponível em:

http://www.portaltransparencia.gov.br/. Acesso em: 23 abr. 2020.

BRASIL. Decreto-Lei 76.593/1975. Institui o Programa Nacional do Álcool e dá outras Providências. Brasília, DF: Câmara dos Deputados, 1975. Disponível em: https://www2.camara.leg.br/legin/fed/decret/1970-1979/decreto-76593-14-novembro-1975425253-norma-pe.html. Acesso em: 16 abr. 2020.

CORRÊA, Roberto Lobato. As pequenas cidades na confluência do urbano e do rural. São Paulo: GEOUSP - Espaço e Tempo, São Paulo, v. 15, n. 3, p. 5-12, 2011. Disponível em: http://www.revistas.usp.br/geousp/article/view/74228. Acesso em: 2 jun. 2020.

CORRÊA, Roberto Lobato. Estudos sobre a rede urbana. Rio de Janeiro: Bertrand Brasil, 2006. 
DELGADO, Guilherme. Reestruturação econômica do agronegócio. In: João Pedro Stédile e Douglas Estevam (org.). A questão agrária no Brasil: o debate na década de 2000. São Paulo: Expressão Popular, 2000. v. 7, p. 57-88.

ELIAS, Denise. Novas dinâmicas territoriais no Brasil agrícola. In: SPOSITO, Eliseu Savério; SPOSITO, Maria Encarnação Beltrão; SOBARZO, Oscar (org.). Cidades médias: produção do espaço urbano e regional. São Paulo: Expressão Popular, 2006. p. 279-303.

ENDLICH, Ângela Maria. Pensando os papéis e significados das pequenas cidades. 2006. 505 f. Tese (Doutorado em Geografia) - Universidade Estadual Paulista, Presidente Prudente, 2006. Disponível em: https://repositorio.unesp.br/handle/11449/105037. Acesso em: 29 mar. 2020.

FERREIRA DIAS, Franciele. Pequenas cidades na rede urbana de Ourinhos-SP: agronegócio e especialização produtiva. 2019. Tese (Doutorado em Geografia) Universidade Estadual de Londrina, Londrina, 2019. Disponível em: http://www.bibliotecadigital.uel.br/document/?code=vtls000228452. Acesso em: 23 mar. 2020.

FRESCA, Tânia Maria. Centros locais e pequenas cidades: diferenças necessárias. Mercator, Fortaleza, n. 9, n. 20, p. 75-8, 2010. Disponível em: http://www.mercator.ufc.br/mercator/article/view/398. Acesso em: 24 jun. 2020.

FRESCA, Tânia Maria. O papel das pequenas cidades na rede urbana do Oeste Paulista. In: ENCUENTRO DE GEÓGRAFOS DE AMERICA LATINA, 4., 1993, Merida. Anais [...]. Merida: Faculdade de Los Andes, 1993. p. 181-190.

FUNDAÇÃO SEADE; EMPRESA PAULISTA DE PLANEJAMENTO METROPOLITANO. Rede urbana e regionalização do Estado de São Paulo. São Paulo: Emplasa, 2011. Disponível em:

http://www.seade.gov.br/produtos/publicacoes/pub_RedeUrbanaRegionalizacaoESP_2011.p df. Acesso em: 12 ago. 2020.

IBGE. A geografia da cana-de-açúcar: dinâmica territorial da divisão territorial do trabalho. Rio de Janeiro: IBGE, 2017b. Disponível em:

https://www.ibge.gov.br/geociencias/organizacao-do-territorio/analises-do-territorio/18939-ageografia-da-cana-de-acucar.html. Acesso em: 28 jun. 2020.

IBGE. Censo agropecuário. Rio de Janeiro: IBGE, 2017a. Disponível em: https://www.ibge.gov.br/estatisticas/economicas/agricultura-e-pecuaria/9827-censoagropecuario.html?=\&t=0-que-e. Acesso em: 22 nov. 2020.

IBGE. Estimativas da população. Rio de Janeiro: IBGE, 2020a. Disponível em: https://ftp.ibge.gov.br/Estimativas_de_Populacao/Estimativas_2020/estimativa_dou_2020.pd f. Acesso em: 12 nov. 2020.

IBGE. Regiões de influência das cidades. Rio de Janeiro: IBGE, 2020b. Disponível em: https://biblioteca.ibge.gov.br/index.php/biblioteca-catalogo?view=detalhes\&id=2101728. Acesso em: 20 out. 2020.

INSTITUTO DE PESQUISA ECONÔMICA APLICADA. Caracterização e tendências da rede urbana do Brasil. Brasília: IPEA, 2000. (Coleção Pesquisa, 3 v.), Disponível em: https://www.ipea.gov.br/portal/index.php?option=com_content\&view=article\&id=18261. Acesso em: 5 abr. 2020.

OLIVEIRA, Bianca Simoneli; SOARES, Beatriz Ribeiro. Cidades locais do triângulo mineiro e Alto Parnaíba/MG. Caminhos da Geografia, Uberlândia, MG, v. 3, n. 5, p. 52 - 72, 2002. Disponível em: http://www.seer.ufu.br/index.php/caminhosdegeografia/article/view/15290. Acesso em: 29 jun. 2020.

SANTOS, Milton. A natureza do espaço. São Paulo: Edusp, 2014. 
SANTOS, Milton. Manual de geografia urbana. São Paulo: Edusp, 2008.

SANTOS, Milton. O Espaço dividido. São Paulo, Edusp, 2004.

SÃO PAULO (Estado). Lei no 11.241/2002. Dispõe sobre a eliminação gradativa da queima da palha da cana-de-açúcar e dá providências correlatas. São Paulo, SP: Assembleia Legislativa, 2002. Disponível em: https://www.al.sp.gov.br/repositorio/legislacao/lei/2002/lei11241-19.09.2002.html. Acesso em: 16 abr. 2020.

SELANI, Reinaldo Luiz. A evolução da cana-de-açúcar no escritório de desenvolvimento rural (EDR) de Ourinhos e o papel das esferas públicas e das agroindústrias do açúcar e do álcool no processo de organização do espaço. 2005. Dissertação (Mestrado em Geografia) - Universidade Estadual Paulista Júlio de Mesquita Filho, Rio Claro, SP, 2005. Disponível em: https://repositorio.unesp.br/handle/11449/95616. Acesso em: 30 jun. 2020.

VEIGA, José Eli da. Cidades imaginárias: O Brasil é menos urbano do que se calcula. São Paulo: Universidade de São Paulo, 2002.

VEIGA, Leia Aparecida. Jaguapitã-PR: pequena cidade da rede urbana norte-paranaense especializada na produção industrial de mesas de bilhar. 2007. Dissertação (Mestrado em Geografia) - Centro de Ciências Exatas, Universidade Estadual de Londrina, Londrina, 2007. Disponível em:

http://bdtd.ibict.br/vufind/Record/UEL_7005e6512a5eaafa077ac5f8720d7561. Acesso em: 8 ago. 2020.

Recebido: agosto de 2020. Aceito: janeiro de 2021. 